\title{
Temporal trends and spatial structures of the sea surface temperature in the Bay of Biscay
}

\author{
Constantin KOUTSIKOPOULOS $^{a *}$, Pierre BEILLOIS $^{b}$, Claude LEROY $^{\mathrm{b}}$, Françoise TAILLEFER $^{\mathrm{c}}$ \\ ${ }^{a}$ University of PATRAS, Department of Biology, 26500 Patra, Greece \\ ${ }^{b}$ IFREMER, B.P. 21105, 44311 Nantes cedex 3, France \\ ${ }^{\mathrm{c}}$ Météo France, CNRM/GMAP/AAD, 42 avenue G. Coriolis, 31057 Toulouse cedex, France
}

(Revised 12/01/98, accepted 14/01/98)

\begin{abstract}
A time series spatial grid of sea surface temperature (SST) data provided by the archives of Meteo-France and covering the period 1972-1993 was analysed in order to define both the long-term and periodic (mainly seasonal) components at diflerent locations in the Bay of Biscay. The study confirmed the existence of a long-term increasing trend in the SST, but showed that this trend was not homogeneous over the entire area. It revealed also that the amplitude of the cyclic components (summcr-winter differences) is spatially heterogeneous. The south-eastern part of the Bay of Biscay, close to the French-Spanish border, shows the stronger warming trend (a mean increase of $1.4{ }^{\circ} \mathrm{C}$ for the period 1972 1993). This trend decreases in the adjacent regions and is not statistically significant in the northern part of the bay and the Celtic Sea. The increasing trend was recorded both in winter and summer periods with the winter slopes being slightly higher. The amplitude of the SST seasonal changes (summer-winter differences) is stronger close to the southern French Atlantic coast in the area off the Gironde estuary. The lowest values were observed in the SW of the bay in the region of intense upwelling processes. Finally, the analysis of the main components of this series provides a simple empirical model describing the time-related changes in the SST. This model could be useful for studies in the field of biological oceanography and in the context of comparative studies. The possible linkage of these observations with changes in the structure of ecosystem in this area is also discussed. (C) Elsevier, Paris
\end{abstract}

Bay of Biscay / sea surface temperature / time series / long-term trend / seasonal changes

Résumé - Tendances temporelles et structures spatiales de la température de surface de la mer dans le golfe de Gascogne. Une série chronologique de températures de surface de la mer (SST) a été analysée pour estimer les tendances à long terme et les composantes périodiques (principalement saisonnières) en différents points d'une grille, dans le golfe de Gascogne. Les données, couvrant la période 1972-1993, sont des valeurs décadaires moyennes fournies par MeteoFrance. Le réchauffement à long terme est confirmé, avec une réparition hétérogène, observée également pour l'amplitude de la composante périodique (différence été-hiver). Dans le sud-est du golfe, vers la frontière franco-espagnole, le réchauffement est plus élevé (en moyenne 1,4 ${ }^{\circ} \mathrm{C}$ de 1972 à 1993). La tendance s'atténue dans les secteurs voisins et devient négligeable dans le nord du golfe et dans la mer Celtique. Le réchauffement, enregistré aussi bien en hiver qu'en été, est un peu plus marqué en hiver. L'amplitude des variations saisonnières de la température de surface est plus prononcée près de la côte dans le secteur influencé par l'estuaire de la Gironde. Les plus faibles différences entre l'été et l'hiver sont observées dans le sud-ouest du golfe, où les phénomènes d'upwelling sont intenses. L'analyse principales composantes du signal SST fournit un modèle empirique simple décrivant les variations temporelles de la température de surface de la mer. Ce modèle pourrait s'appliquer en océanographie biologique, dans le cadre d'études comparatives. Les liens possibles entre ces observations et les variations de structure de l'écosystème sont également disculés. @ Elsevier, Paris

golfe de Gascogne / température de surface de la mer / série chronologique / tendance à long terme / variation saisonnière

* Correspondence and reprints 


\section{INTRODUCTION}

The analysis of data sets of the earth's surface temperature (including continents, islands and ocean surface) reveals an increase by $\approx 0.5{ }^{\circ} \mathrm{C}$ over the last 100 years with the decade of $1980 \mathrm{~s}$ being the warmest on record [1]. Pingree in 1994 [4] presented a data set of winter sea surface temperature (SST) off the Spanish coast in the south Bay of Biscay. This record shows an increasing trend in the mean January SS'I from 1972 to 1993 reaching $1.5^{\circ} \mathrm{C}$ for the entire period.

The temperature of a water mass is mainly determined by three principal heat fluxes: heat exchanges at the atmosphere-ocean interface, heat transfert by advection and turbulent diffusion and heat exchanges on the sea bottom (which are generally negligible). Therefore, the SST' is a synthetic parameter influenced by climatic, meteorological, hydrodynamic and topographic parameters. Because the distribution in space of these parameters is not homogeneous, the analysis of long-time SST series over large spatial scales could reveal differences in both the longterm changes and the periodic fluctuations between arcas underlying the influence of one or several of the parameters.

If Pingree's observation [4] is not limited locally but concerns a larger area, then this long-term trend in the abiotic parameters could have important consequences on the structure and functioning of the marine ecosystem. Changes could occur in the productivity of the pelagic ecosystem or in the geographic distribution of important species accompanied by modifications of the individual growth rates that are linked to the temperature. Several changes in morphometric population characteristics, the presence of new species or the structure of the marine communities have been previously reported in the Bay of Biscay [2, 5, 6, 9]. Therefore, a further analysis of the prior mentioned changes in SST is of great importance for the field of biological oceanography and marine ecology.

Pingree's observation [4] leads naturally to two questions: Is the recorded increasing trend in the SST the result of a winter warming or it is a general shift marking all the seasons? Is this phenomenon limited to the SW of the Bay of Biscay or does it extend over a larger area? These questions will be examined here. The analysis of the SST time series will also lead to the definition of a simple empirical model describing both the mean longterm and the seasonal changes in SST in the Bay of Biscay. This model can be a useful tool for research projects in the field of biological oceanography.

\section{THE DATA}

The exchanges of energy at the ocean-atmosphere interface seriously affect the climatic conditions. These fluxes are conditioned by the existing differences between the temperature of the sea surface and that of the lower layers of the atmosphere. Consequently, the SST is an important input parameter for the meteorological models. For this reason, from the early 1970s the French National Service of Meteorology (Météorologie Nationale) has collected information on the SST from selected vessels and meteorological buoys in order to use these elements in weather prediction models. The spatial distribution of the measurement points (vessels and buoys) is rather random; thus, the computation of a regular grid containing SST values and respecting the characteristics of the meteorological models is necessary. Comments on the interpolation methods used to generate this grid have becn presented by Ratier [7] and Taillefer [8]. These authors explain that the interpolation process smooths the original data, eliminating the spatially limited structures and local anomalies.

After the generation of the grid, several parameters are archived. The data used in this work was obtained from these archives. Each grid intersection corresponds to the mean SST per 10-d period so the high frequency fluctuations have been discarded. Some changes have been performed during the last 20 years in the structure of these archives leading to the storage of different types of SST grids. In the present work, we used two different grids containing SST values. The first one covers the area

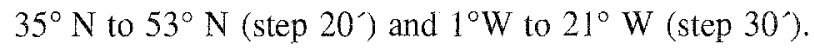
This grid covers the period from 1972 to July 1988 . The second one has the following definition: $24^{\circ} 45^{\prime} \mathrm{N}$ to $72^{\circ} 45^{\prime} \mathrm{N}\left(\right.$ step $\left.45^{\prime}\right)$ and $44^{\circ} \mathrm{E}$ to $84^{\circ} \mathrm{W}$ (step $1^{\circ}$ ). This series starts in August 1987 and covers the period up to the end of 1993. As the resolution of the grids may have an influence on the interpolated values, we tested the compatibility of the two series for their common 19871988 period and in common points. The results showed very slight differences, which for the present study could be disregarded. This element justifies the construction of the single time series used in this work.

The points retained in this study correspond to intersections of one of the two grids (several are common intersections of the two grids; figure 1). Every time an intersection of the grid did not match the points of the other grid an interpolated value was computed using only the four values entouring the desired point (the inverse 


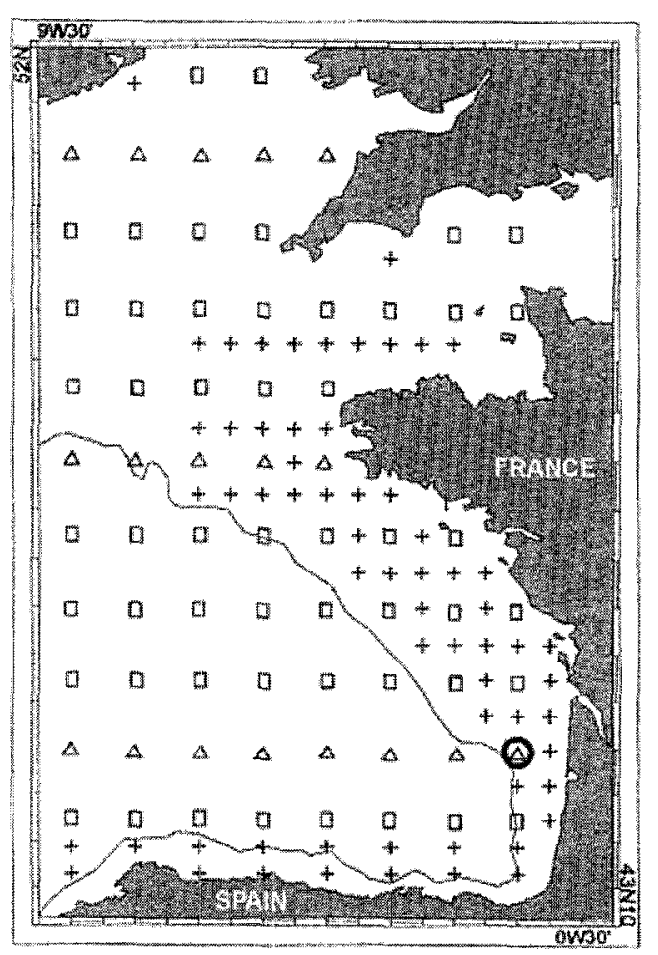

Figure 1. Set of points for which sea surface temperature (SST) series for the period 1972-1993 were analysed. The circled triangle is presented in the text as the 'reference point' $\left(45^{\circ} \mathrm{N}, 2^{\circ} \mathrm{W}\right)$ and serves to present the adopted analysis (crosses: grid 1; squares: grid 2; triangles: common points of the two grids; see text).

distance squared method was used for the interpolation). Therefore, only local information was used and the smoothing consequences of this additional interpolation were limited. In this way, complete time series containing the mean SST per 10-d period were obtained in each point of figure 1 (36 values per year, 792 values for the entire series).

\section{ANALYSIS}

At each point of the Bay of Biscay presented in figure 1, the following analysis has been applied. A step-by-step explanation of the method is presented in figure 2 and concerns the selected point indicated in figure 1 (point with coordinates $45^{\circ} \mathrm{N}, 2^{\circ} \mathrm{W}$ ). Both long-term and cyclic components are included in the original SST series (figure $2 a$ ). First, the coefficients of a linear model were estimated (least squares) corresponding to the quasilinear trend suggested by Pingree's data [4] for the SSI of the south-western part of the Bay of Biscay and the period 1972-1993. This long-term trend was removed and the periodic components were then searched in the resi-duals of the linear model. The autocorrelation diagram of the residuals of the linear trend shows clearly the exis-tence of a strong cyclic component of period 36 corres-ponding to 1 year (figure $2 c$ ). This 1 -year period is the main signal in the original series and is responsible for $91 \%$ of the whole variance of the series. Using an iterative process, a least squares estimate of the amplitude and the phase of this component were estimated, and the remaining residuals after the extraction of this 1-year period component are presented in figure $2 d$. As the autocorrelation diagram shows, there is another cyclic component less significant than the first one with a period of 18 (hall-year). In fact, this second component explains only $3 \%$ of the variance of the original SST series. After the extraction of this second cyclic component the remaining residuals do not contain any other important periodic component (figure $2 f$, g). Therefore, the following empirical model has been retained to describe the SST series at the different points:

$$
\begin{aligned}
& T=a+b t+a_{36} \cos \left[2 \pi / 36\left(c_{36}+t\right)\right] \\
& +a_{18} \cos \left[2 \pi / 18\left(c_{18}+t\right)\right]+\varepsilon
\end{aligned}
$$

where $T$ is the sea surface temperature for the period $t$. The value of $t$ is computed as $t=(y y-1972) 36+d$

with $y y$ the year of the estimate and $d$ the decade (10-day period, 1 to 36) in this year. $a$ and $b$ are, respectively, the intercept and the slope (long-term rate of temperature change) of the linear trend. The nature of the amplitude $\left(a_{36}, a_{18}\right)$ and the phase $\left(c_{36}, c_{18}\right)$ are presented in figure 3 . Considering the major contribution of the first harmonic component, the phase $c$ is determined by the date of the highest temperature (usually late August at these latitudes) and the amplitude $a$ corresponds to the half difference between the highest and the lowest temperature of the year (usually observed in late February) and $\varepsilon$ are residuals which in practice represent temperature 'anomalies.' It is clear that the harmonic component with the 1 -year period has the major contribution in the series. The amplitude of the second component is very low and its contribution limited. Its presence is explained by the nature of the time-related changes in the SST. In fact, the SST is marked by two relatively long periods with little changes (winter, summer) followed by periods showing rapid temperature changes in spring and autumn. Thus, this second cyclic component contributes to the formation of the two plateaux and the definition of the periods of rapid changes. 


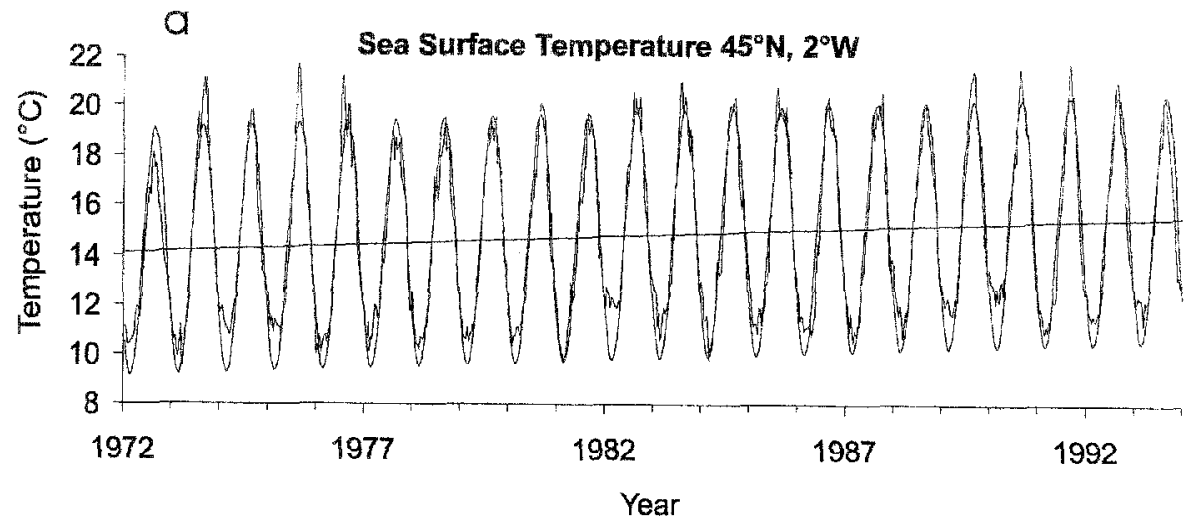

$b$
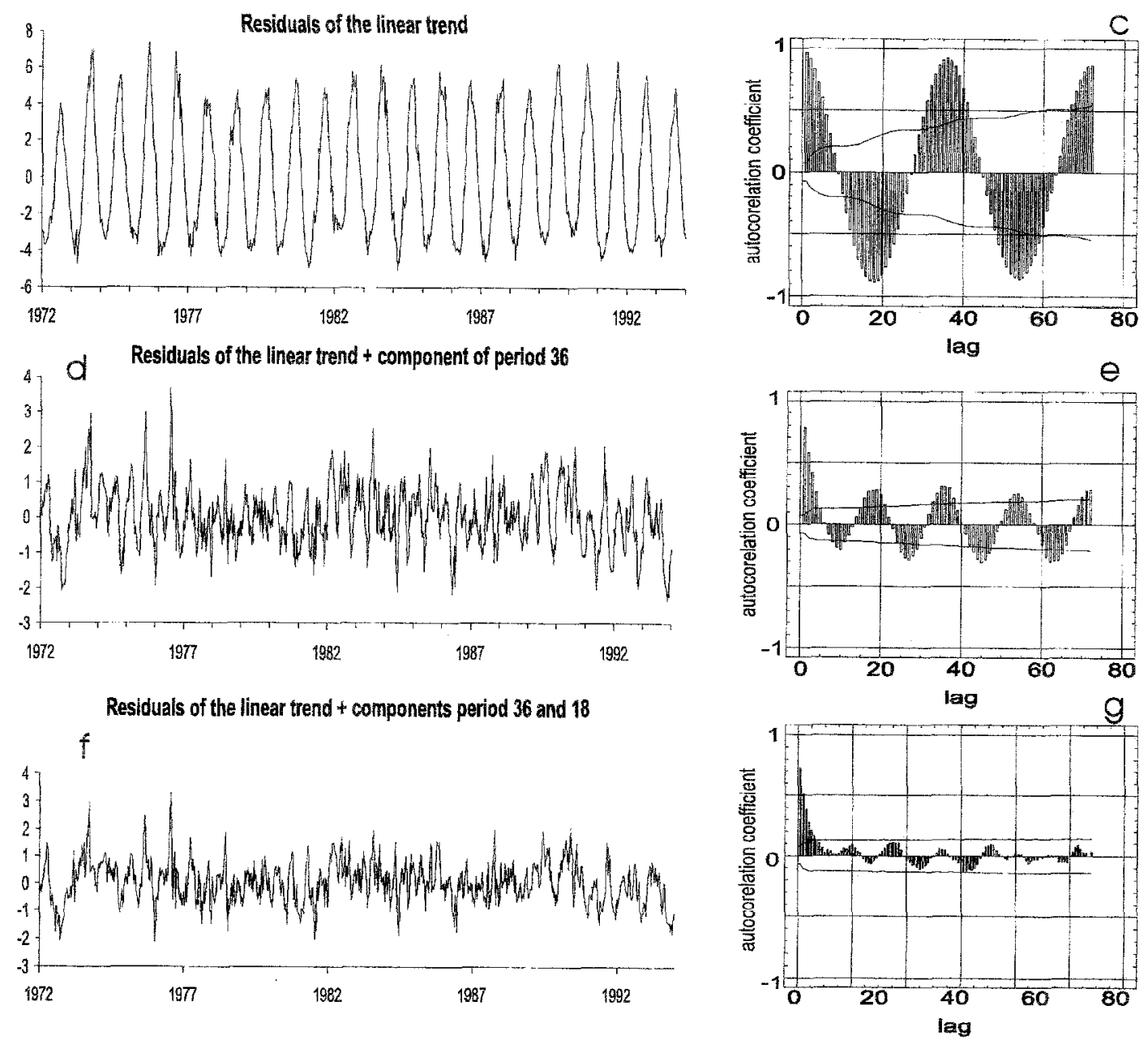

Figure 2. (a) The original sea surface temperature (SST) time series with the estimated linear trend and the predicted values of the empirical model describing the mean time-related changes of SST at the 'reference point' in the Bay of Biscay. (b) Remaining residuals after extraction of the linear trend. (c) Autocorrelogram of the linear residuals (lag: $10 \mathrm{~d}$ ). (d) Residuals after extraction of the linear trend and a cyclic component with 1-year period (36 lags). (e) Autocorrelogram of the remaining residuals after extraction of the linear trend and the 1-year period cyclic component (lag: 10 days). (f) Residuals after extraction of the linear trend and two cyclic components with 1-year and half-year periods (36 and 18 lags, respectively). (g) Autocorrelogram of the f series. 


\section{Sea Surface Temperature (mean 1972-1993) $45^{\circ} \mathrm{N}, 2^{\circ} \mathrm{W}$}

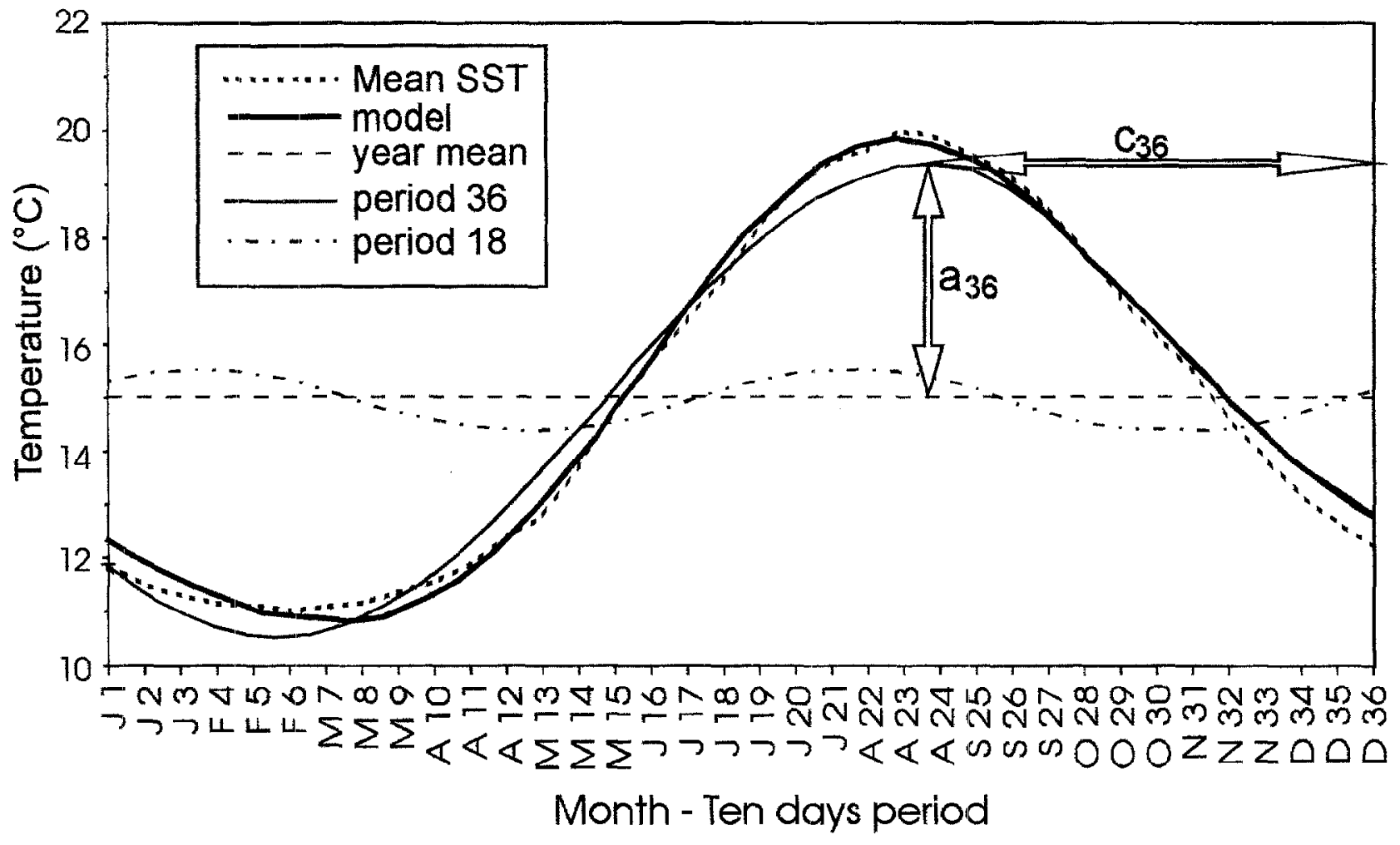

Figure 3. The dotted line represents the mean sea surface temperature (SST) per 10-d period computed from the entire series (1972-1993) for the 'reference point'. The solid, thick line shows the predicted SST values. The horizontal dashed line indicates the mean annual temperature computed from the entire series. The solid thin line represents the cyclic component with 1-year period. The dashed, dotted line indicates the half-year period cyclic component. The arrows $a_{36}$ and $c_{36}$ present the amplitude and phase, respectively, of a cyclic component with 1-year period (see text).

A second question concerns the season that contributes to the long-term changes. Are the changes due to modifications of the mean winter or summer temperatures? To answer this question the mean winter (January-March) and summer period temperatures (July-September) were computed for the years 1972-1993. The linear trend for these two data sets was estimated and figure 4 gives the results for the reference point of figure 1. Obviously, the winter slope appears stronger than that of the summer, but no significant statistical difference was detected.

This analysis, including the summer and winter estimates, was applied at each point of figure 1. Consequently, it is interesting to produce maps with the values of the parameters of the model. In this way, interesting elements about the spatial structure of the SST can be obtained.

\section{RESULTS}

The estimates of the linear trend and the coefficients of the cyclic components for the Bay of Biscay and adjacent sectors are presented in figure 5. The spatial distribution of the slope of the linear trend shows clearly that the SE part of the bay (close to the French-Spanish border) is marked by higher values. Thus, the rate of increase of the SST in this region is stronger than in the adjacent areas. In the shaded regions of the map (southern Brittany, Celtic Sea) the slope is not significantly different from zero (95\% significance level).

The distribution of the coefficient $a$ (intercept) corresponding to the mean annual SST, shows a clear latitudinal trend with the southern areas considerably warmer. The Celtic Sea appears $2{ }^{\circ} \mathrm{C}$ colder than the southern Bay of 


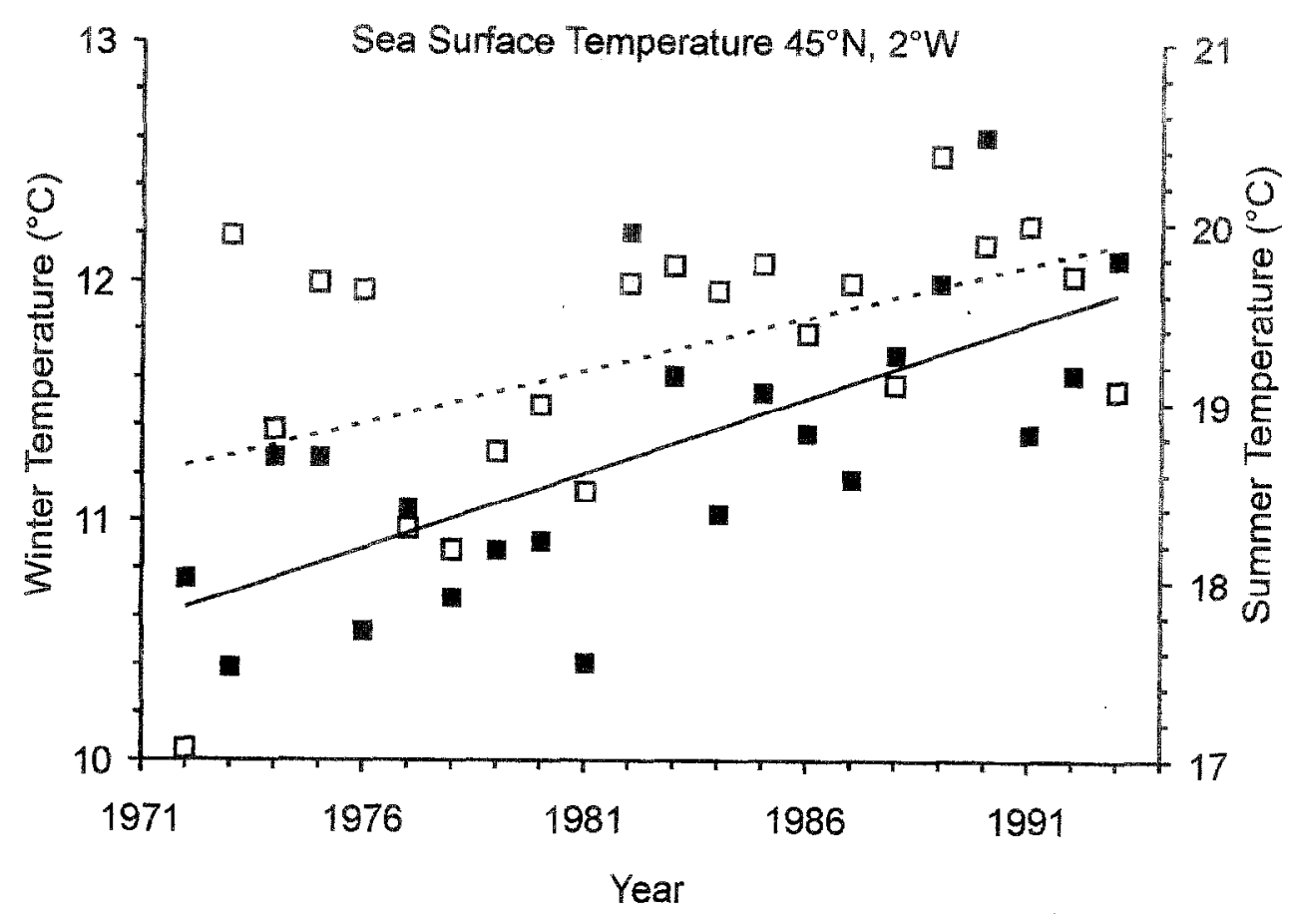

Figure 4. Comparison of long-term changes (trends) in the mean annual winter (closed squares) and summer sea surface temperature (SST) (open squares) for the 'reference point'. Winter includes SST values from January to March and summer corresponds to the July to September period. Solid and dashed lines are the linear trend of the winter and summer data set respectively.

Biscay. The distribution of the coefficients of the 1-year period cyclic component, which is the main signal in the series, also reveals some interesting features. The higher values of the $a_{36}$ coefficient, which is the amplitude of the cyclic component and corresponds to the half summer and winter SST difference, are observed over the southern French continental shelf in the area influenced by the Gironde estuary. In this area a mean difference of $9^{\circ} \mathrm{C}$ between summer and winter was recorded. The cold freshwater discharge in winter and the runoff of warmer continental waters in summer are probably responsible for this difference. In spite of the high similarity both in the seasonal changes and in the values of the freshwater runoff of the Gironde and Loire estuaries, the values of this coefficient remain lower in the region under the influence of the Loire plume, which is located in the northern Bay of Biscay. This could be due to the larger shelf and the increase of the strength of the tidal currents, which contribute to the vertical mixing of the water column towards the north of the bay. The lowest summer-winter difference is observed in the SW area, which is marked by important upwelling processes. The distribution of the $c_{36}$ coefficient (phase) values shows that the oceanic region of the bay reaches its maximum SST values slightly later in summer, but the difference is limited (about 1 week). The distribution of the half-year period component coefficient $a_{i 8}$ shows a main onshore gradient with lower values close to the French Atlantic coast. This means that the plateau characterising the lower SST values in winter and the higher in summer is limited. In other words the time period of high or low values is limited in the coastal areas in contrast with the oceanic sectors where the SST remains at its higher (lower) values for a longer period. No clear feature appears from the distribution of the $c_{18}$ coefficient. In this case also a mean value of 13.5 could be used all over the area with no significant decrease in precision.

The estimates of the rate of long-term changes in the mean winter and summer temperatures show clearly that the two seasons contribute equally to the global increase of the SST values observed during the 1972-1993 recordings. Figure 6 presents the spatial distribution of these estimates where both the seasonal values and distributions in space are very similar.

Finally, figure 5 provides the possibility to obtain an empirical estimate of the SST for a given location and a 
Figure 5. Spatial distribution of the coefficients of the proposed empirical model: slope and intercept of the linear trend, amplitude (a) and phase (c) of the two retained cyclic components with periods 1 year (36) and half a year (18), respectively. In the grey areas the slope is not different from zero (significance level $95 \%$ ).
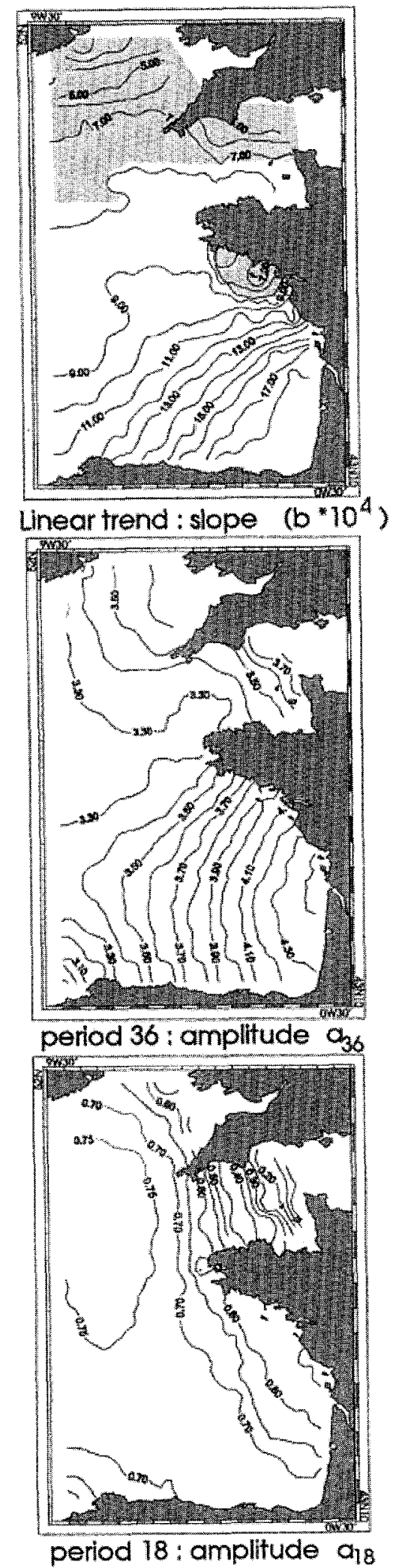
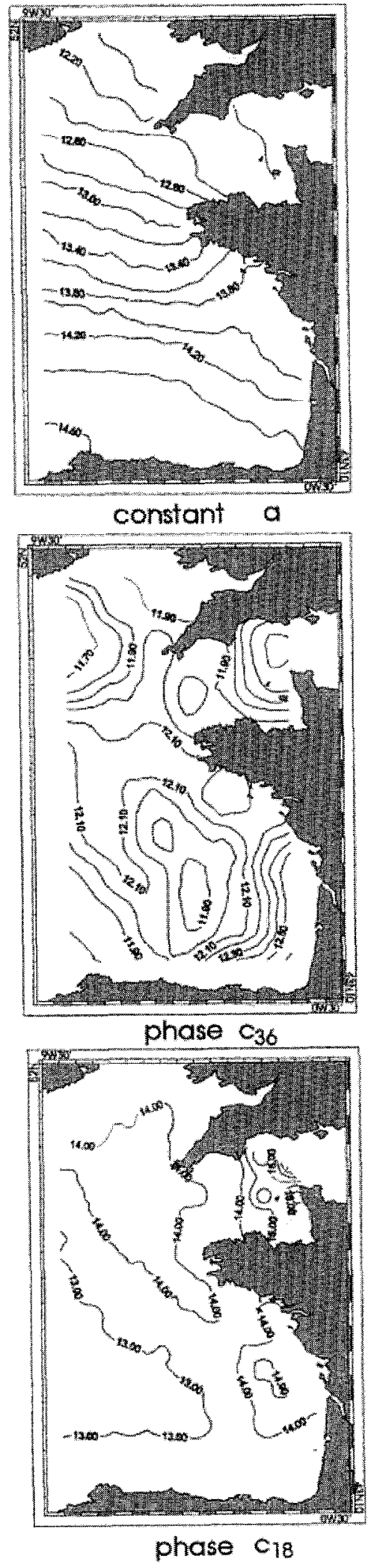


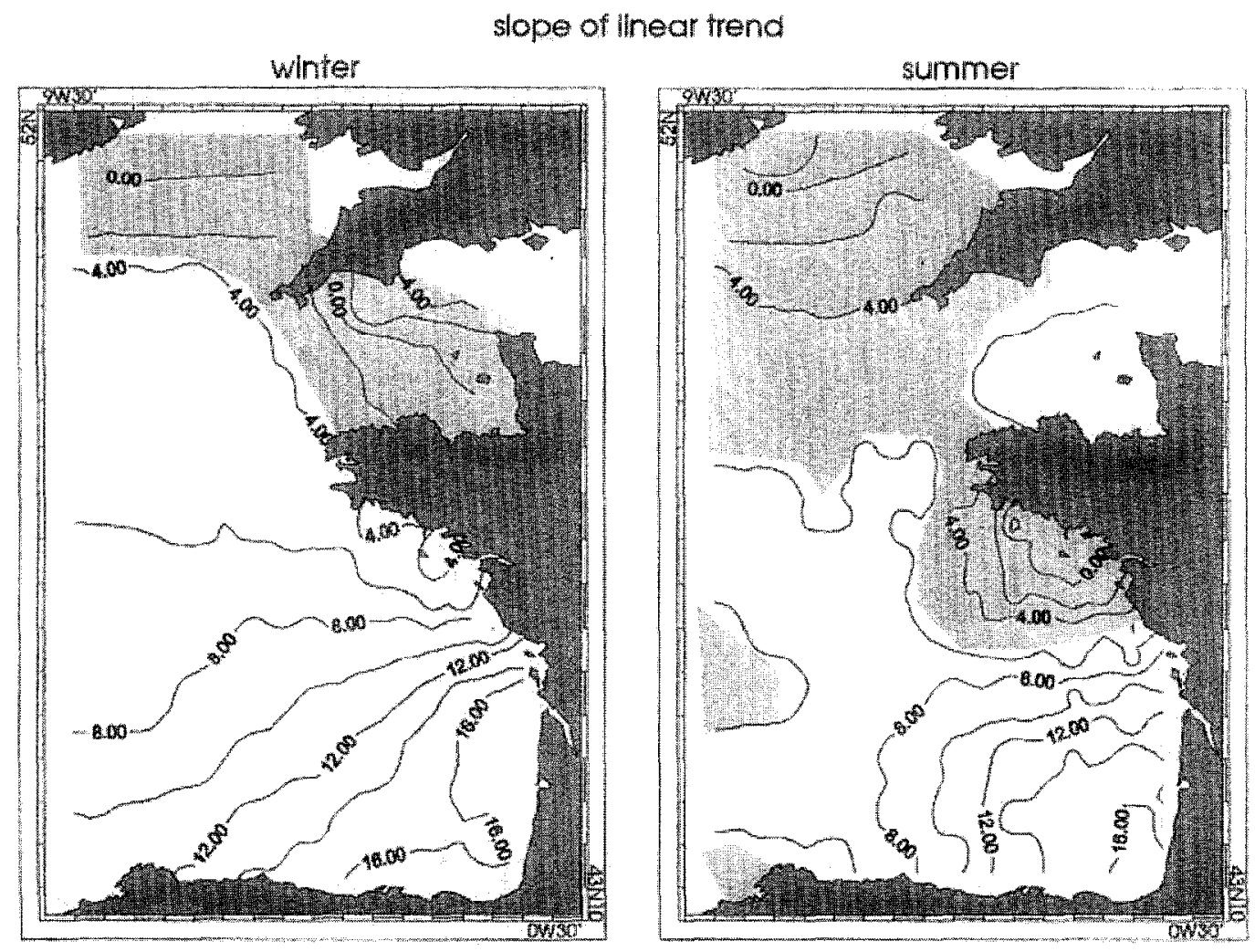

Figure 6. Spatial distribution of the slope of the linear trend (rate of increase) estimated from the mean annual winter (left) and summer (right) sea surface temperature (SST) values. In the grey areas the slope is not different from zero (significance level $95 \%$ ).

precise date using the following model, which is the identical to that presented earlier but in this case the time $t$ is equal to $(1972$-year $) * 365.25+d$, where $d$ is the day of the year (the coefficient $q$ is equal to $36 / 365.25$ ).

$T=a+b q t+a_{36} \cos \left[2 \pi / 365.25\left(c_{36} / q+t\right)\right]$

$+a_{18} \cos \left[2 \pi / 182.625\left(c_{18} / q+t\right)\right]+\varepsilon$

\section{DISCUSSION}

The main information provided by the present study concerns the increasing trend of the mean SST in the Bay of Biscay during the period 1972-1993. Although the 1980 s has been recognised globally as the warmest of the last 100 years [1], the present study revealed that the warming trend was not homogeneous at the scale of the Bay of Biscay and the adjacent sectors. The south-eastern part of the bay showed the stronger warming trend and the mean increase of SST was $1.4{ }^{\circ} \mathrm{C}$ from 1972 to 1993.
This warming trend decreased in the adjacent regions. The analysis also confirmed that the warming trend concerns the mean annual temperature. The trend was recorded both in winter and summer periods with the winter slopes slightly higher but not statistically different. This observation completes the study of Pingree [4] which showed a winter warming trend in the south-western slope region of the bay and the elements provided by Valencia and Borja (unpublished data) but also at a local scale.

The reasons for the spatial limitation of the warming trend in the south-eastern part of the Bay of Biscay are not clear. This area has some particular meteorological, oceanographic and topographic features-a synthesis of which was presented by Koutsikopoulos and Le Cann [3]. At a seasonal scale the spring increase of the SST starts earlier and is more pronounced in the south-eastern part of the bay. The summer SST is also higher in this area. Already in 1942 Sverdrup et al. in their world oceans maps [10] showed higher August SST values in this area 
than in the adjacent sectors. The water temperature has an important influence on the productivity of the pelagic ecosystem. Because this parameter is determined by a combination of climatic, meteorological, oceanographic and topographic features, any long-term change in SST reflects changes in the abiotic characteristics of the ecosystem. Changes with marked local or regional character can affect the structure of the pelagic community. There are several biological observations that can be reasonably linked to the physical fragmentation of the Bay of Biscay and the recorded long-term changes:

- Junquera and Perez-Gandaras [2], based on morphometric and meristic characters of the anchovy (Engraulis encrasicolus L.), concluded that individuals sampled in the north-west Iberian Peninsula are different from those found in the south-east Bay of Biscay. Using a similar approach, Prouzet (IFREMER St Pée/Nivelle, personal communication) showed that morphological differentiation can also be observed in anchovy individuals from different locations of the south-eastern part of the bay.

- A strong biological gradient has been repeatedly observed in the middle of the French continental shelf (close to the latitude of the 'plateau de Rochebone', $46^{\circ} \mathrm{N}$ ), separating clearly temperate fish species in the northern part and fish species with warm affinities in the south [5].

- The same author observed that a population of Argyrosomus regius (maigre) exists in the southern Biscay area. The two other known populations of this species are located further south in warmer areas of the African coast.

- Recent biologicall observations reveal an increasing trend in the abundance of species with warm affinities [6] which appeared recently in the bay and spread northward. Although the majority concern species living close to the bottom, a correlation appears with the rising SST.

- Sauriau [9] analysed published information over the last 90 years indicating that, since 1983, Cyclope neritea (eurythermic gastropod) has extended its range towards the north. Although this rapid spread is linked to the commercial transport of oysters, the author suggests that the recent changes in the climatic conditions in the Bay of

\section{REFERENCES}

Biscay (rising temperatures) contributed to the survival and settlement of the species.

The analysis of the SST data in the present study provided an empirical model describing the time-related changes in SST. This model describes both the long-term trend and the seasonal changes of the SST. The long-term trend corresponds to a linear increase of the SST during the period 1972-1993 with a rate of about $0.064{ }^{\circ} \mathrm{C}$ per year. The seasonal changes in the SST signal differ slightly from a simple 1-year period sinusoidal signal. The recorded series is marked by two flat areas in winter and summer where the rate of change is very low. These plateaux are linked by transition periods (spring, autumn) with high rates $\left(\approx 1{ }^{\circ} \mathrm{C}\right.$ per $10 \mathrm{~d}$ in early June). To reproduce these characteristics a second harmonic component with a half-year period must be added to the main 1-year period harmonic component. The contribution of this second component is limited. It explains only $3 \%$ of the total variability of the series. The maps of figure 5 and the proposed empirical model describe the mean temporal evolution of the SST in any area of the Bay of Biscay. It could be a practical tool for the planification of biological oceanography field studies because temperature governs the basic metabolism of individuals and energy tranferts at the major levels of the food web.

It is also important to note that this global analysis of the already smoothed by different processes SST signal revealed some of the well known hydrological structures in the area such as the Iberian Peninsula upwelling, the oceanic zone of the bay with its eddies, the French shelf with the important Gironde and Loire estuaries (extended discussion on the characteristics of these structures can be found in [3]). Thus, the procedure leading to the construction of the SST grids conserves the main information contained in the original data.

Finally, the southern part of the Bay of Biscay seems to have some original characteristics compared to the neighbouring oceanic areas; however, these singularities are supported by scattered observations, in time and space, which do not allow us to link the physical observations to the biological ones, because of the dramatic lack of basic ecological knowledge in that area.
[1] Jones P.D., Wigley T.M.L., Folland C.K., Parker D.E., Angell J.K., Lebedeff S., Hansen J.E., Evidence for global warming in the last decade, Nature (1988) 332-790.
[2] Junquera S., Pere:-Gandaras G., Population diversity in Bay of Biscay anchovy (Engraulis encrasicolus L. 1758) as revealed by multivariate analysis of morphometric and meristic characters, ICES J. Mar. Sci. 50 (1993) 383-391. 
[3] Koutsikopoulos C., Le Cann B., Physical processes and hydrological structures related to the Bay of Biscay anchovy, Scientia Marina 60 (2) (1996) 9-19.

[4] Pingree R.D., Winter warming in the southern Bay of Biscay and Lagrangian eddy kinematics from a deep-drogued Argos buoy, J. Mar. Biol. Assoc. U.K. 74 (1994) 107-128.

[5] Quéro J.C., Dardignac J., Vayne J.J., Les poissons du golfe de Gascogne. Publ. IFREMLR (1989) 229 p.

[6] Quéro J.C., Du Buit M.H., Vayne J.J., Données ichtyologiques sur le réchauffement des eaux Atlantiques Européennes, Oceanol. Acta 21 (2) (1998) 341-347.
[7] Ratier A., Température de la mer et analyse objective, Met, Mar. 130 (1986) $\$ 3-17$.

[8] Taillefer F., Le point sur les modèles d'analyse en exploitation à la Météorologie Nationale, Met. Mar. 146 (1990) 7-11.

[9] Sauriau P.G., Spread of Cyclope neritea (Mollusca: Gastropoda) along the north-eastem Atlantic coasts in relation to oyster culture and to climatic fluctuations, Mar. Biol. 109 (1991) 299-309.

[10] Sverdrup H.U., Johnson M.W., Fleming R.H., The oceans, their physics, chemistry and biology, Prentice-Hall, Inc., 1942, $1060 \mathrm{p}$. 